\title{
No mundo maravilhoso do futebol
}

\section{Patrícia Azevedo \\ Murilo Godoy \\ Julian Germain}

No mundo maravilhoso do futebol é um trabalho de fotografias e escrita realizado a partir do encontro dos artistas Patrícia Azevedo, também professora da Escola de Belas Artes da UFMG, Murilo Godoy, designer, e Julian Germain, fotógrafo, com as crianças e jovens moradores do Morro do Cascalho, na zona Oeste de Belo Horizonte. Logo na entrada dessa comunidade existe um campo de futebol, onde muitos moradores praticam o esporte ou apenas se encontram para jogar conversa fora.
O público de Belo Horizonte pôde conhecer o resultado do trabalho numa exposição realizada no Centro Cultural da UFMG, em outubro de 1996. Essa exposição também foi levada para a cidade do Porto, Portugal, em agosto de 2000, a convite do Centro Português de fotografia. Depois, algumas fotografias foram publicadas no livro No mundo maravilhoso do futebol (1998), de onde foram extraídas as onze imagens que se seguem. 


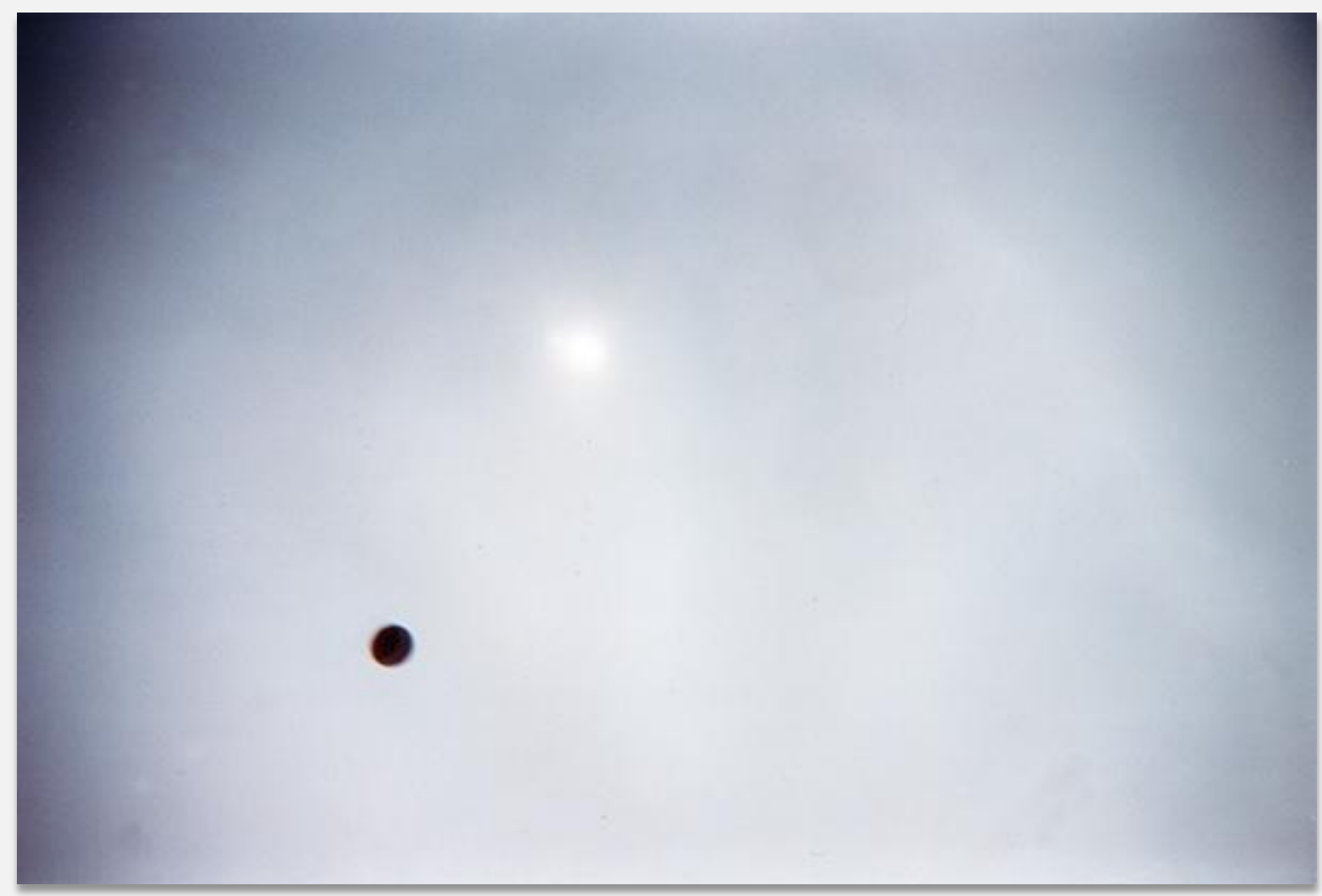

Gleison da Silva Luís 


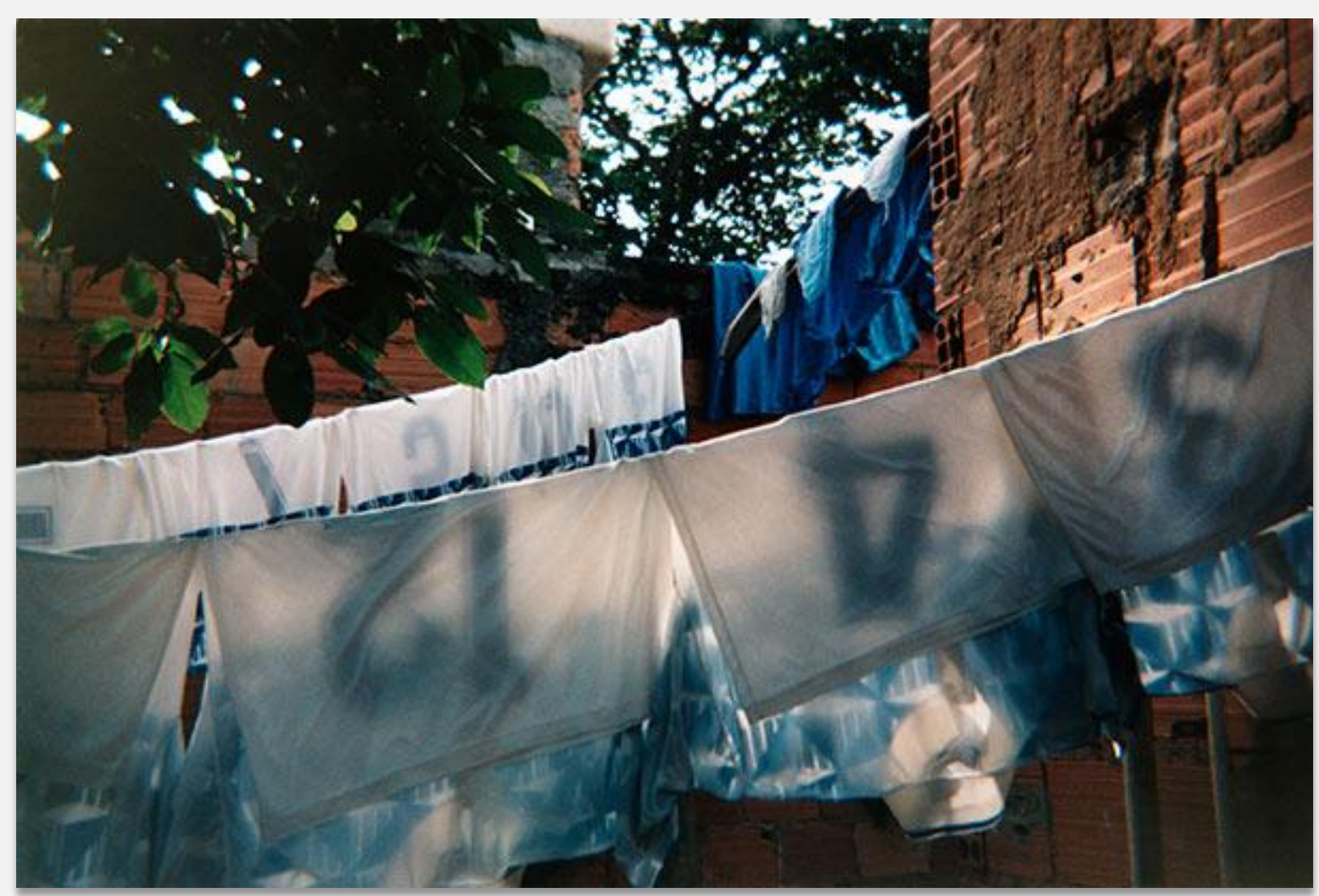




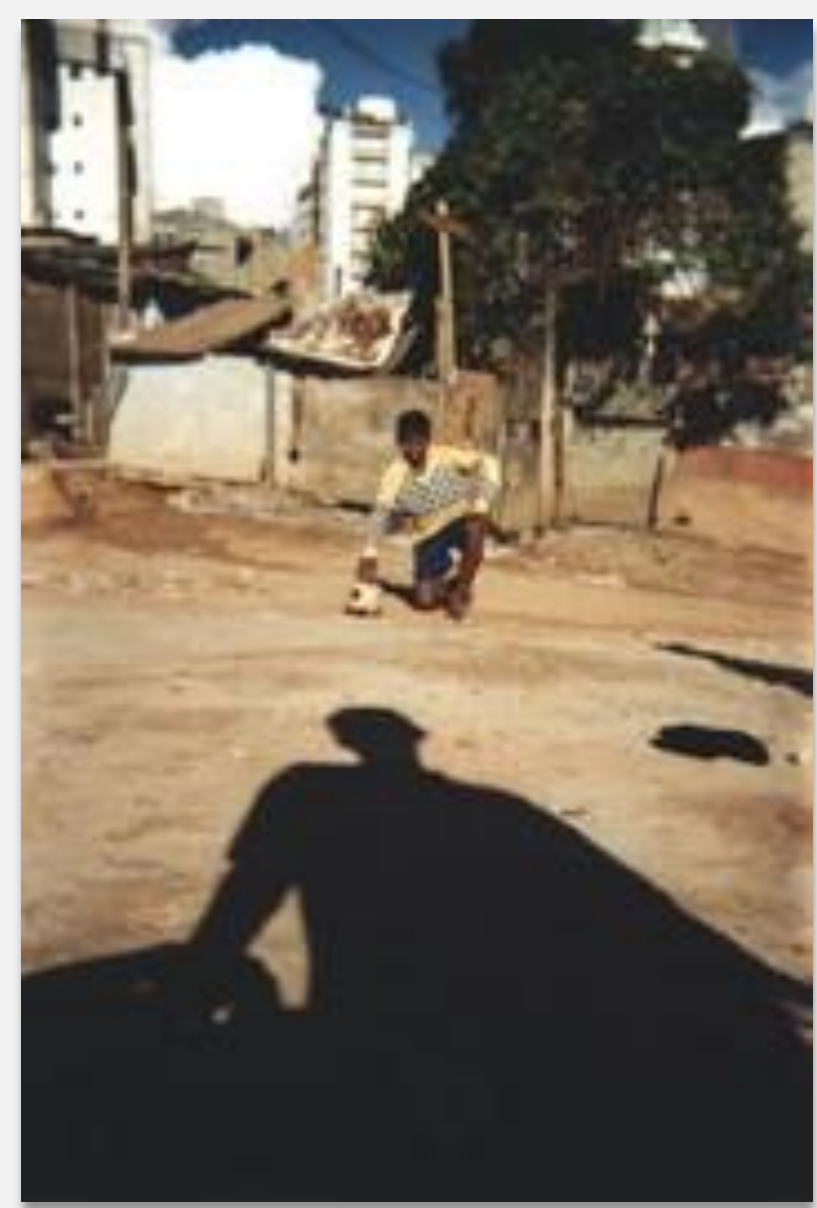




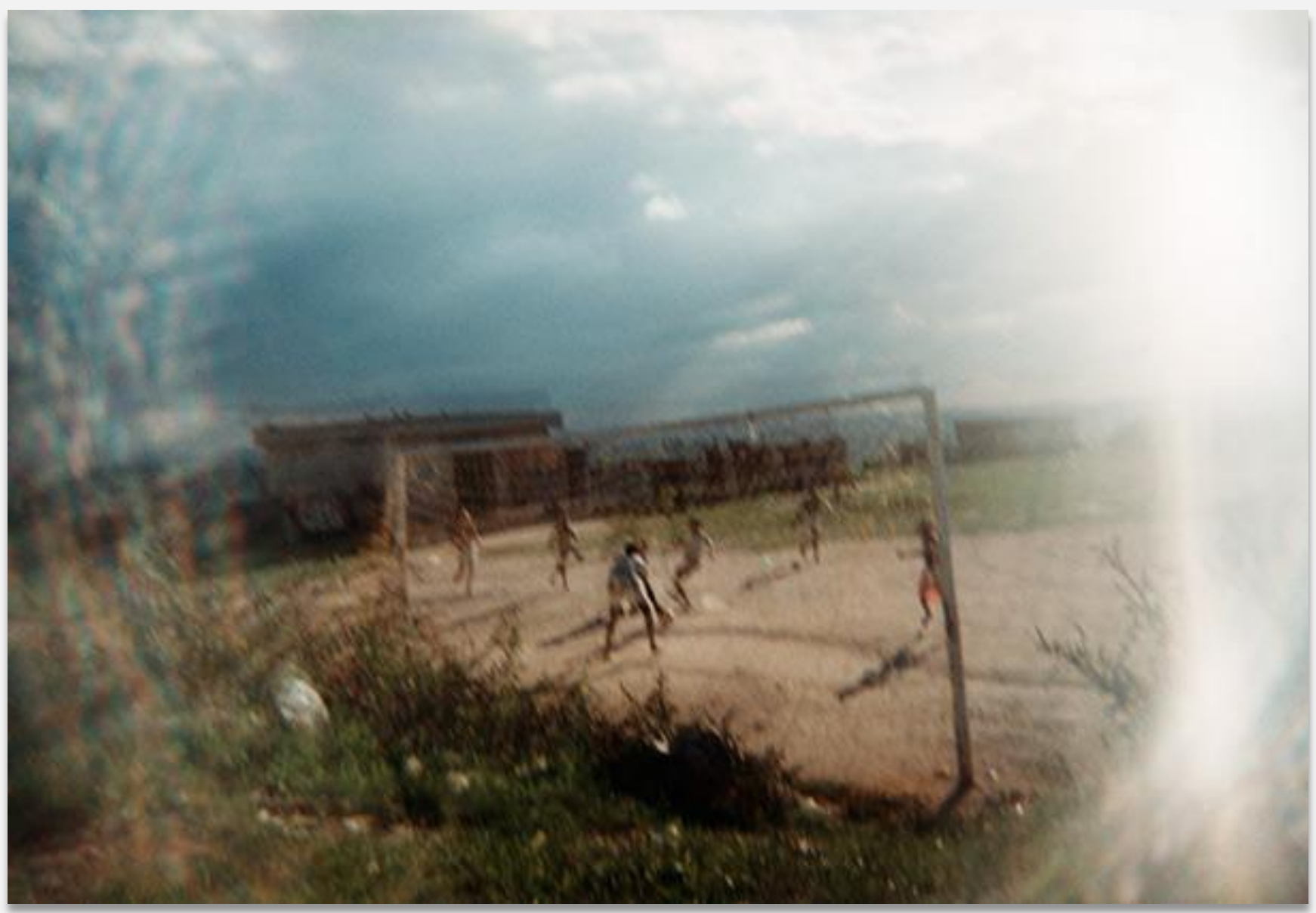

Emerson Teixeira 


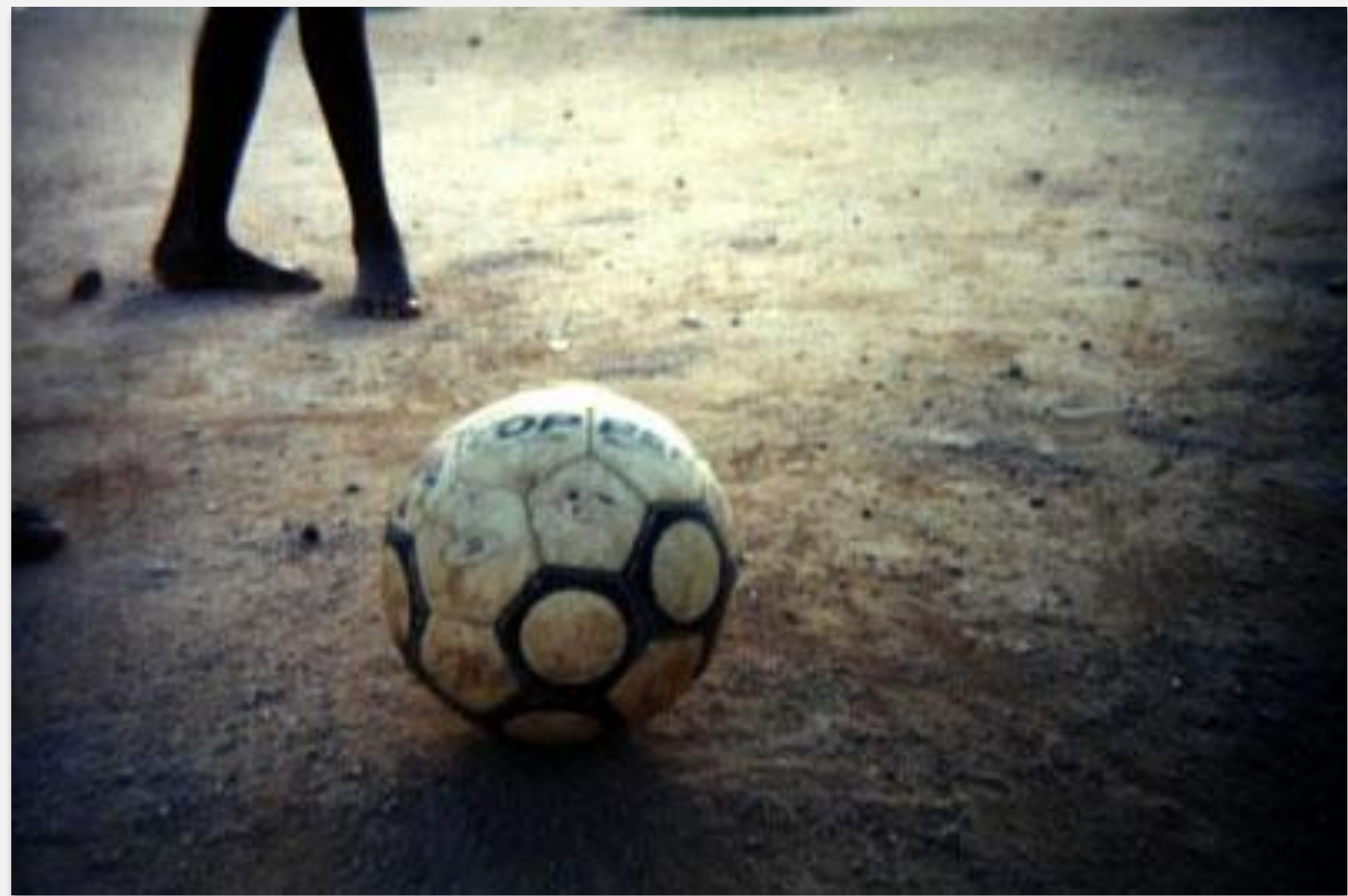

Marcelo Gomes dos Santos 


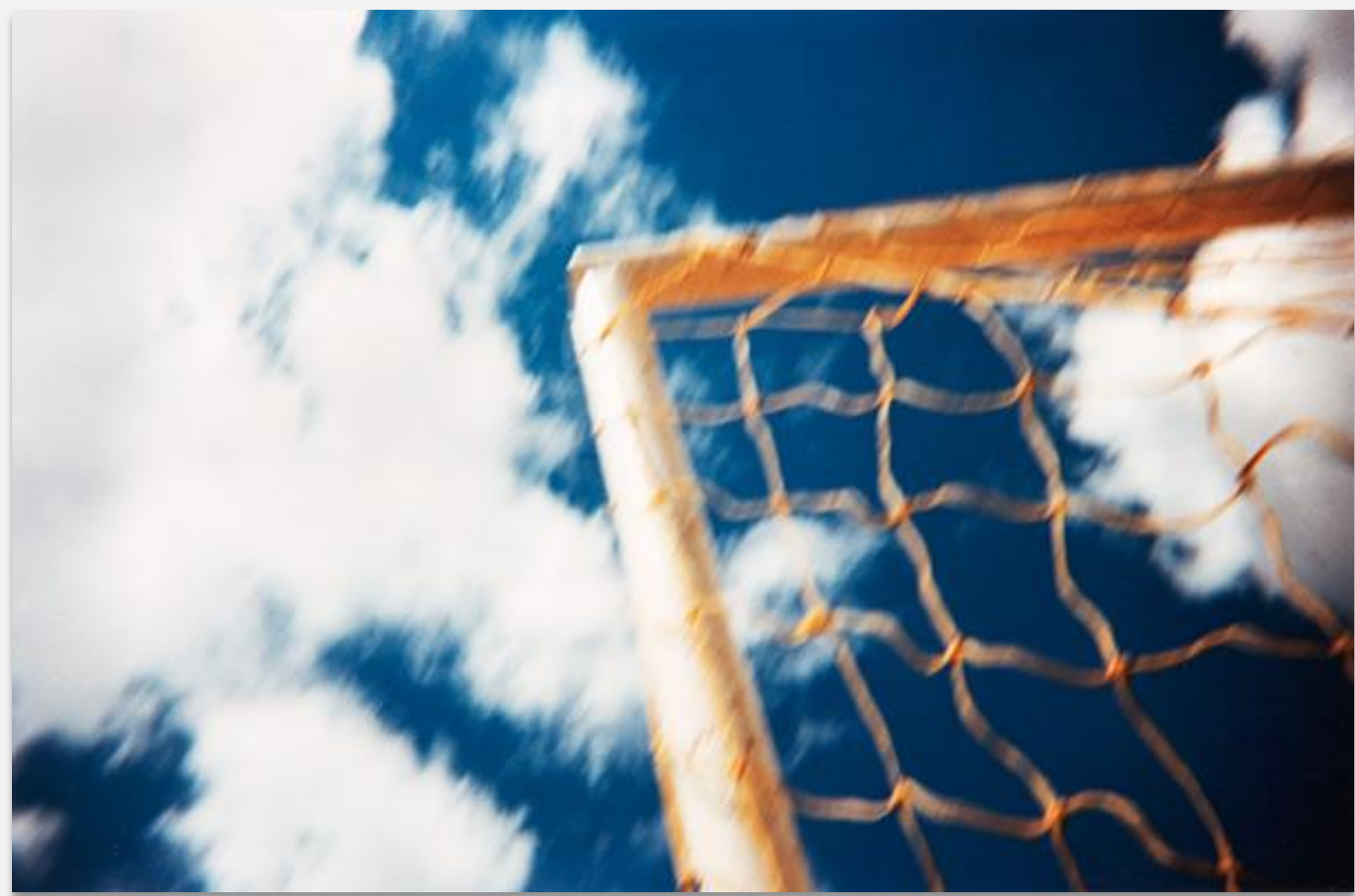

Marcos Antônio Barbosa dos Santos (Capa do 1ํㅡúmero da revista FuLiA / UFMG, 2016) 


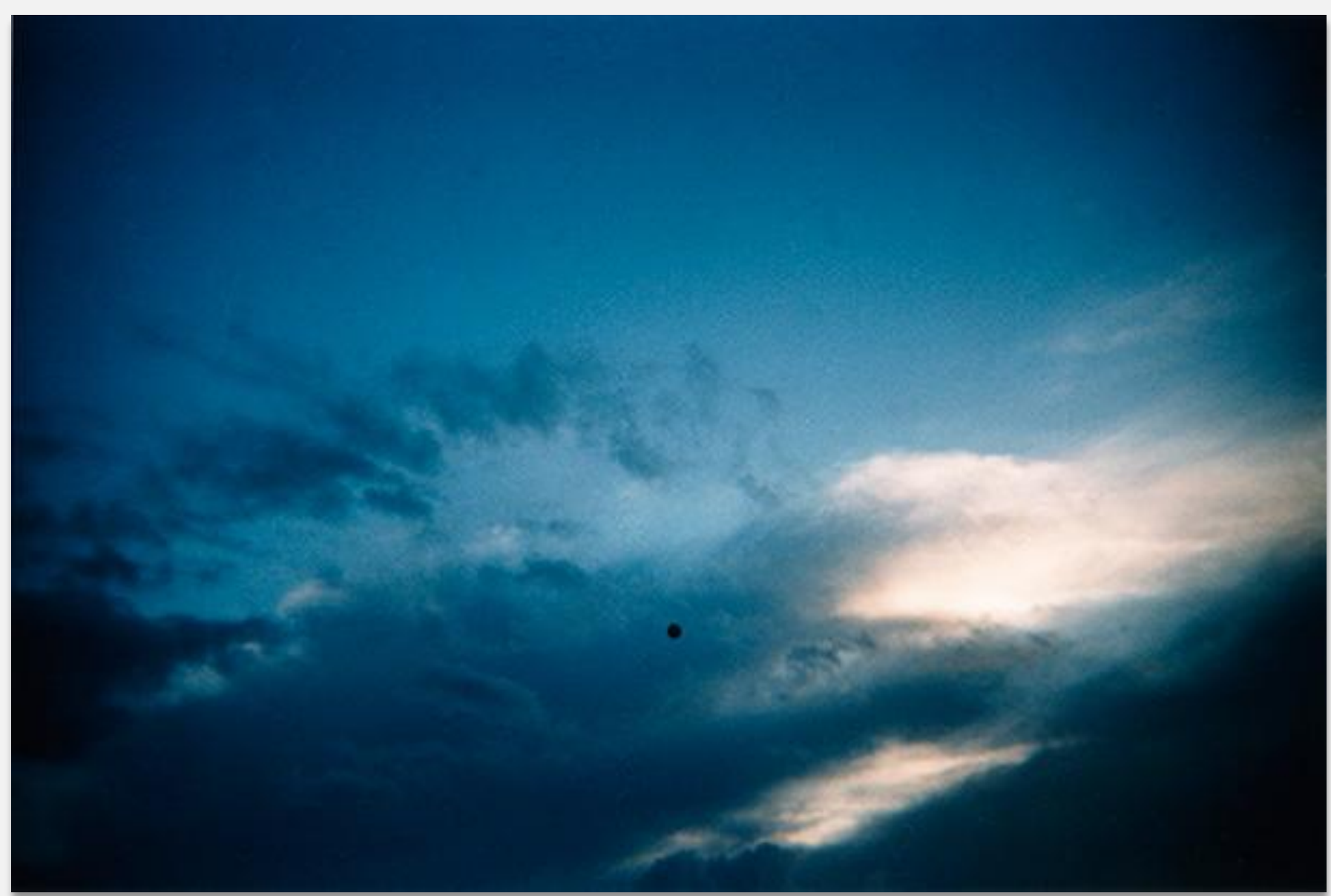

Elinto Firmino de Almeida 


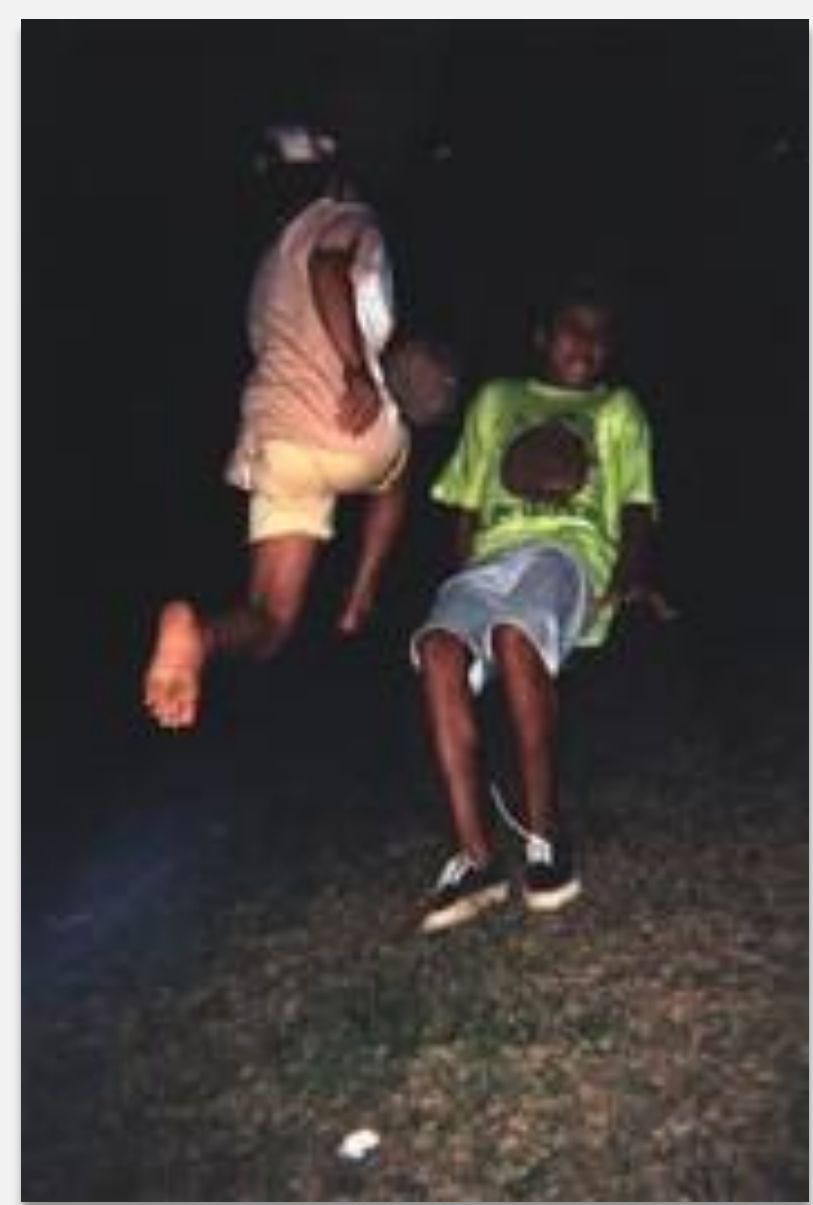




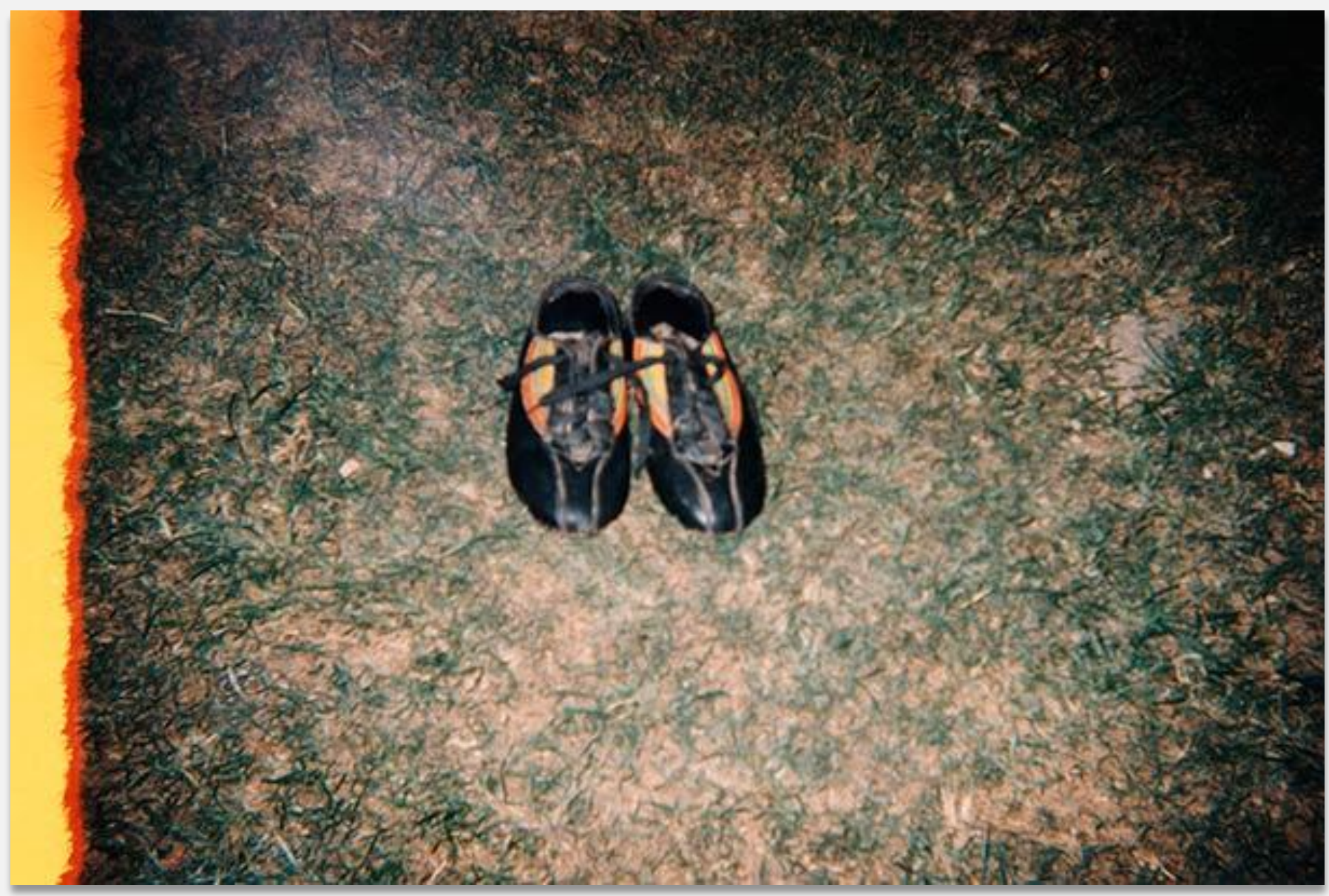

Carlos André Cecílio 
FuLiA / UFMG - No mundo maravilhoso do futebol

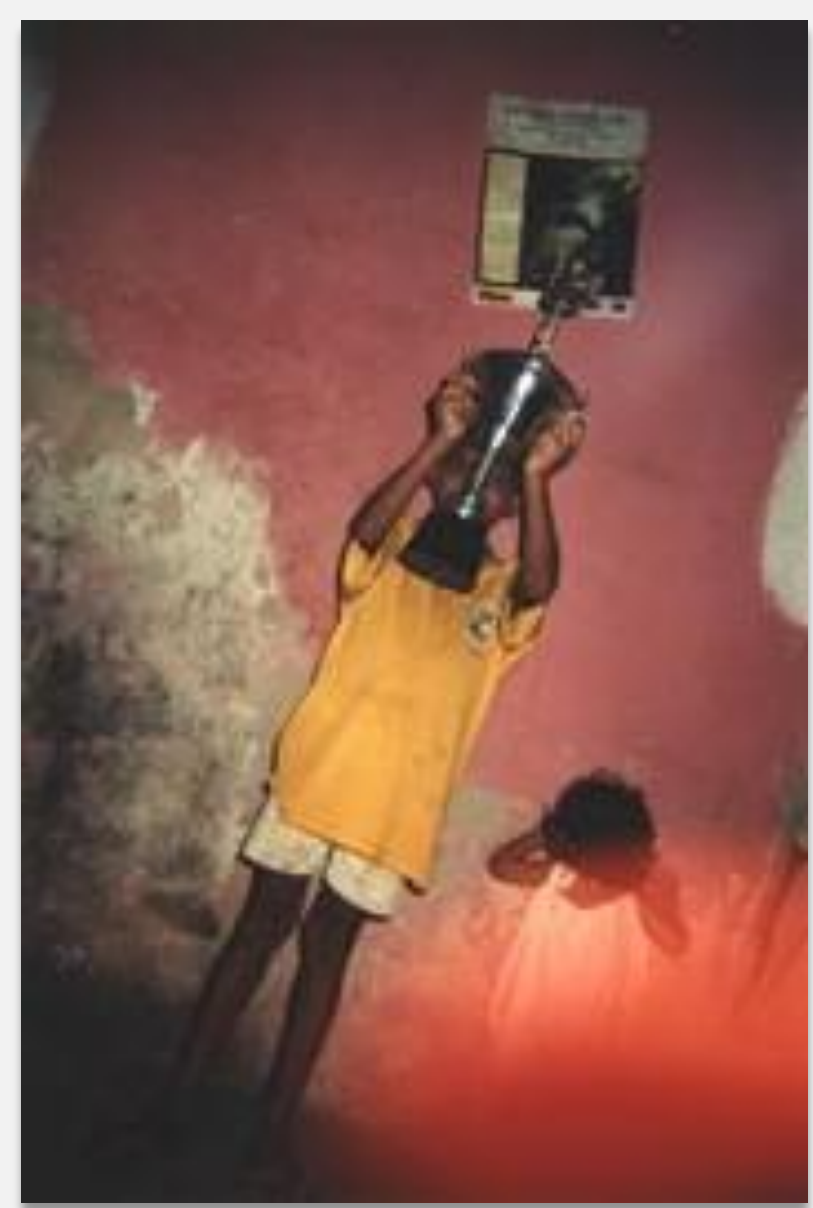

Aldair José Antônio da Silva 


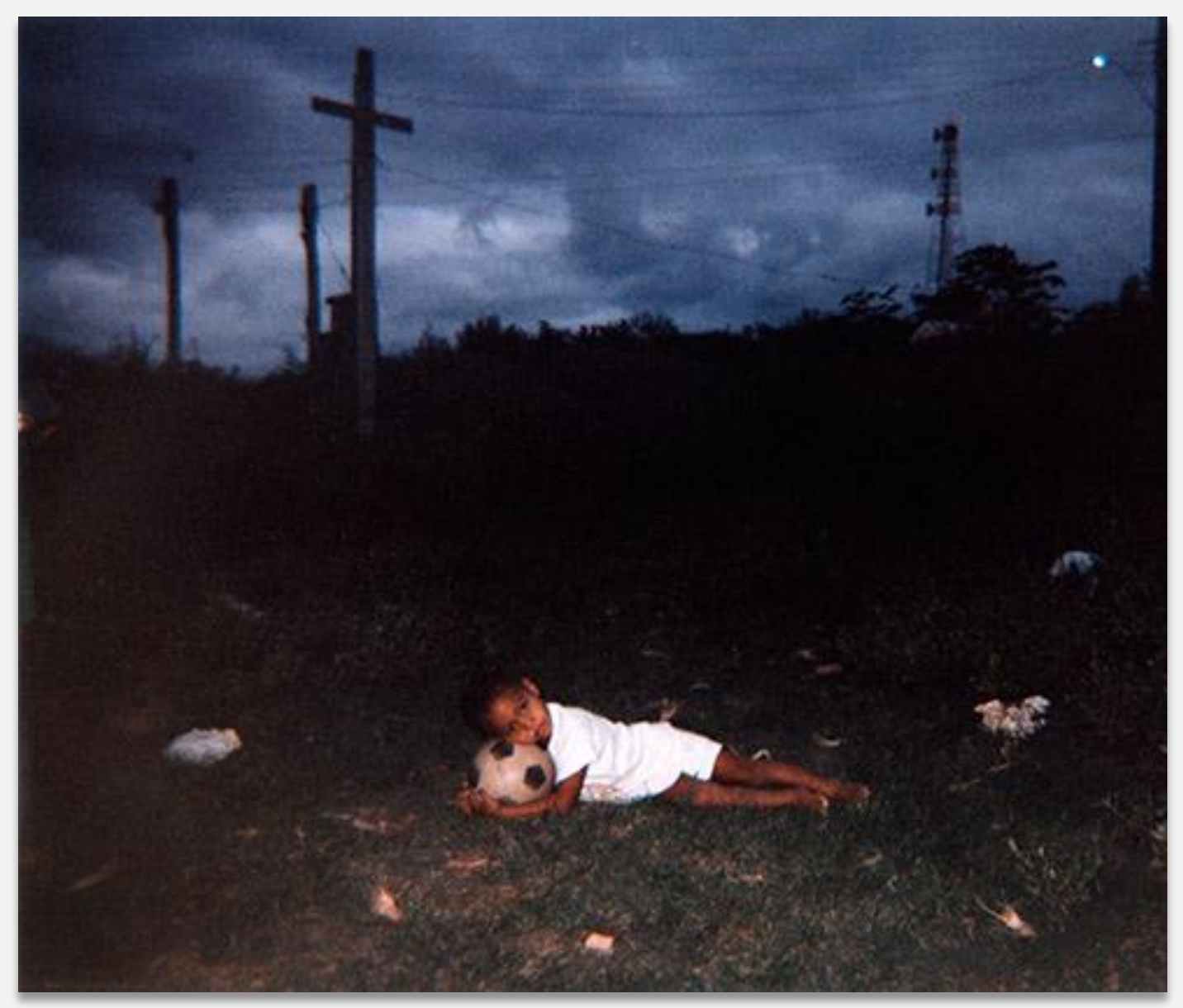

Daniel Luís da Silva 